\begin{tabular}{|l|l|l||}
\hline \multicolumn{2}{|c|}{ PublisherInfo } \\
\hline \hline PublisherName & $:$ & BioMed Central \\
\hline \hline PublisherLocation & $:$ & London \\
\hline \hline PublisherImprintName & $:$ & BioMed Central \\
\hline \hline
\end{tabular}

\title{
Primate mitochondrial evolution
}

\begin{tabular}{|l|l|l||}
\hline \multicolumn{3}{|c|}{ ArticleInfo } \\
\hline \hline ArticleID & $:$ & 4354 \\
\hline \hline ArticleDOI & $:$ & $10.1186 /$ gb-2002-3-8-reports0040 \\
\hline \hline ArticleCitationID & $:$ & reports0040 \\
\hline \hline ArticleSequenceNumber & $:$ & 21 \\
\hline \hline ArticleCategory & $:$ & Paper report \\
\hline ArticleFirstPage & $:$ & 1 \\
\hline \hline ArticleLastPage & $:$ & 4 \\
\hline \hline & & RegistrationDate : 2002-4-26 \\
ArticleHistory & $:$ & Received $\quad: 2002-4-26$ \\
& & OnlineDate $\quad 2002-8-1$ \\
\hline \hline ArticleCopyright & $:$ & BioMed Central Ltd2002 \\
\hline \hline ArticleGrants & $:$ & \\
\hline \hline
\end{tabular}




\begin{tabular}{|l|l|l|}
\hline ArticleContext & $:$ & 130593388 \\
\hline
\end{tabular}

\section{Diane P Genereux}

\section{Summary}

Disparity between primate phylogenetic trees that are based on mitochondrial versus nuclear DNA is likely to be due to differences between lineages in nucleotide substitution bias in the mitochondrial genomes

\section{Significance and context}

The relationship of the tarsiers (Tarsius species) to other primates has long been uncertain. Nuclear DNA data identify Tarsius as the sister taxon of the anthropoids (the great apes) but mitochondrial data do not provide robust support for this conclusion. Positive selection, biased nucleotide replacement, or some combination of the two, could be responsible for the discordance between the mitochondrial and nuclear trees. A recently constructed primate phylogeny using retrotransposons provides compelling evidence that the nuclear DNA tree is the true species tree. Although interesting in its own right, confirmation of the true phylogeny does not elucidate the force or forces responsible for the disparity between the mitochondrial and nuclear trees. Schmitz et al. have used comparative genome sequence analysis to distinguish between alternative possible explanations.

\section{Key results}

The authors conducted a detailed comparative study of primate mitochondrial genomes. They sequenced the 16,927-nucleotide mitochondrial genome of Tarsius bancanus, and acquired complete mitochondrial genome sequences for nine other primates and 13 non-primate mammals from public databases. They aligned both nucleotide and amino-acid sequences and inferred phylogeny by three different methods - maximum parsimony, neighbor joining and maximum likelihood - using the marsupials oppossum and platypus as outgroups. Consistent with historical difficulties in using mitochondrial sequence to infer the true phylogeny of primates, only trees built with protein sequences using maximum parsimony revealed Tarsius and the anthropoids as members of a monophyletic group. All three methods revealed a long branch leading to the anthropoids, suggesting rapid evolution in this branch. Differences in rates of evolution between lineages are well known as potential confounding factors to correct phylogenetic inference, resulting in a phenomenon known as long-branch attraction. 
One hypothesis to explain rapid evolution along the branch leading to the anthropoids is that the ancestors of these primates experienced a period of intense directional selection. Schmitz et al. found evidence of a significant increase in the rate of nonsynonymous $\left(\mathrm{K}_{\mathrm{a}}\right)$, but not synonymous $\left(\mathrm{K}_{\mathrm{s}}\right)$, replacements in the anthropoid mitochondrial lineage compared to the Tarsius mitochondrial lineage. This would seem to suggest a period of strong positive selection along the anthropoid line. However, as the authors note, synonymous sites in lineages that diverged long ago are likely to be saturated with mutations, so that the true rate of synonymous substitution can no longer be discerned. This is particularly true for mitochondrial genomes, whose rate of nucleotide substitution tends to be higher than that of nuclear genomes. Indeed, only human and chimpanzee - the phylogenetically closest pair examined - showed a significant difference in $\mathrm{K}_{\mathrm{s}}$. Schmitz et al. concluded that the relative rates test was not useful to test the selection hypothesis.

An alternative explanation for the observed accelerated evolution is a period of biased nucleotide mutation along the branch leading to the anthropoids. Comparisons of mitochondrial genome nucleotide composition revealed that $T$. bancanus has a composition characteristic of that of non-primate mammals. There is also a significant trend toward the replacement of $\mathrm{T}$ with $\mathrm{C}$ and $\mathrm{A}$ with $\mathrm{C}$ along the branch of the mitchondrial tree leading to the anthropoids. This trend is reflected in the preponderance of A- and T-encoded amino acids in Tarsius compared with the anthropoids. Regression analysis revealed a strong correlation between the amino-acid compositions of the Tarsius and anthropoid genomes and the 'silent' third-position nucleotide compositions of those genomes. A selection-driven change in amino-acid composition would be expected to affect nucleotide composition at nonsynonymous sites only. Therefore, the correlation between third-position nucleotide and amino-acid composition provides evidence that changes in nucleotide composition along the long branch leading to the anthropoids were driven not by selection but by nucleotide substitution bias.

Finally, Schmitz et al. were able to determine that mitochondrial genes transferred to the nucleus retained the base composition they had at the time of transfer, indicating that this biased nucleotide replacement was confined to the mitochondrial genome.

\section{Links}

The Tarsius bancanus mitochondrial genome has been deposited in GenBank under accession number AF348159.

\section{Reporter's comments}

The relative rates test is useless when synonymous sites are saturated, so it is typically difficult to determine whether selection or substitution bias is responsible for accelerated evolution in anciently diverged lineages. Schmitz et al. cleverly use comparative genomic data to avoid this problem. Future work should seek to determine the specific forces and mechanisms responsible for biased nucleotide substitution in the mitochondrial DNA along the branch leading to the anthropoids. 


\section{Table of links}

Molecular\%20Biology\%20and\%20Evolution

GenBank

References

1. Schmitz J, Olme M, Zischler H: The complete mitochondrial sequence of Tarsius bancanus: evidence for an extensive nucleotide compositional plasticity of primate mitochondrial DNA. Mol Biol Evol. 2002, 19: 544-553.

This PDF file was created after publication. 